research and development (ZonMw), the Danish Fors $\varnothing$ gsdyrenes Værn and the Danish in vitro toxicology Network (DK) for the financial support without which this workshop would not have been possible.

More information on already established media can be found on: http://www.focusonalternatives.org.uk/PDFs/FCS-free\%20table\%20May\%2009.pdf; http://www.goodcellculture.com/

\section{References:}

Coecke, S., Balls, M., Bowe, G. et al. (2005). Guidance on good cell culture practice. A report of the second ECVAM task force on good cell culture practice. ATLA 33, 261-287.

ESAC (2008). ESAC statement on the use of FCS and other animal-derived supplements.

Hartung, T., Balls, M., Bardouille, C. et al. (2002). Good Cell Culture Practice. ECVAM Good Cell Culture Practice Task Force Report 1. ATLA 30, 407-414.

van der Valk, J., Brunner, D., De Smet, D. et al. (2010). Optimization of chemically defined cell culture media - Replacing
Fetal Bovine Serum in mammalian in vitro methods. Toxicol. In Vitro, in preparation.

van der Valk, J., Mellor, D., Brands, R. et al. (2004). The humane collection of fetal bovine serum and possibilities for serum-free cell and tissue culture. Toxicol. In Vitro 18, 1-12.
J. van der Valk ${ }^{*}$, M. L. Scarino ${ }^{2}$, L. Knudsen ${ }^{3}$ and G. Gstraunthaler ${ }^{4}$
${ }^{1}$ NCA, Fac. Veterinary Medicine, Utrecht University, The Netherlands,
${ }^{2}$ Istituto Nazionale di Ricerca per gli
Alimenti e la Nutrizione, Rome, Italy,
${ }^{3}$ Department of Public Health,
University of Copenhagen, Denmark,
${ }^{4}$ Department of Physiology, Innsbruck
Medical University, Austria
*Corresponding author:
J.vanderValk@uu.nl

\title{
ETHIOPIA: Alternatives in life science education at Ambo University
}

Ethiopia, 23 ${ }^{\text {rd }}$ December 2009

The Department of Biology at Ambo University in Ethiopia organised a one day seminar-workshop on alternatives to animal use in life science education. The event was held on $23^{\text {rd }}$ December 2009 and organised in collaboration with Mahatma Gandhi-Doerenkamp Center (MGDC) for alternatives at Bharathidasan University in Tamil Nadu, India, the DoerenkampZbinden Foundation (DZF), Switzerland, and I-CARE, Italy.

Ato Lakew Wondimu, Vice President of Ambo University, said in his welcoming address that this seminar was first of its kind in Ethiopia. He congratulated the MGDC, DZF and ICARE for their noble work in protecting animals and propagating the mission of humane education.

P. Natarajan, Professor and Director of CATER, Ambo University, introduced the significance of alternatives in life science studies and research. He stated that the introduction of non-animal teaching aids has decreased animal experimentation in education by $30-50 \%$ in the last 15 to 20 years worldwide.

Mitiku Tesso, President of Ambo University, promised that Ambo University aims to spearhead a movement to bring humane education to Ethiopia and other parts of Africa. He predicted that the concept of humane education would gain momentum in Africa.

The Hon. Adhana Haile, Ethiopian Deputy State Minister for Education, emphasised the importance of developing new programs in biological research and following other countries in introducing humane education.

Mohammad A. Akbarsha, director and chair of the MGDC, fervently appealed to making learning biology lively and useful by using alternatives instead of dissection. He also addressed options for toxicity and pharmacology testing with in vitro alternatives and computer-aided bio-informatics tools, i.e. in silico alternatives.

Subash Chand, Second Secretary to the Indian Embassy at Addis Ababa and Brook Lemma, Director of Research, Addis Ababa University, congratulated Ambo University on organising this unique seminar.

Shiranee Pereira, I-CARE, explained the need to bring the philosophy of "Ahimsa" into the teaching of Life Sciences. She spoke of animal sentience and pain and the need to adopt the 3 Rs concept. Her talk covered details of painful animal experiments conducted in biomedical research and in the production of cosmetics and pharmaceuticals and contrasted these with the alternatives that have replaced eye and skin tests on animals.

M. C. Sathyanarayana, A.V.C. College, India, spoke on dissection alternatives and innovative digitalised alternatives to the use of animals in life science education. He explained that alternatives to dissection are clean, cheaper and safer and allow students to learn at their own pace. They are thus pedagogically, scientifically and ethically superior to conventional animal dissection. He urged Ethiopia to become a forerunner in Africa in starting the movement of humane education and protecting animals from being exploited for the purpose of education, research and testing.

The participants were given hands-on training on the use of tools and software in alternatives in animal science education. There were presented various simulators, mannequins and videos used as alternatives to animal use. 